\title{
Dimensional changes in reconstructed nipples: autologous versus prosthetic breast reconstruction
}

\author{
Chae Eun Yang, Kwang Hyun Park, Dae Hyun Lew, Tai Suk Roh, Dong Won Lee \\ Department of Plastic \& Reconstructive Surgery, Institute for Human Tissue Restoration, Yonsei University College of Medicine, \\ Seoul, Korea
}

\begin{abstract}
Purpose: The creation of the nipple-areola complex is the final stage in breast reconstruction and highly affects patient satisfaction. The neo-nipple is well known to shrink over time, particularly in the nipple projection. Currently, no reconstruction technique is clearly superior in terms of nipple size maintenance. We evaluated nipple size changes among several methods of breast mound reconstruction.

Methods: Seventy-eight patients received nipple-areola complex reconstruction secondarily after breast reconstruction. C-V flap nipple reconstructions were performed using a free transverse rectus abdominis myocutaneous (TRAM) flap in 25 cases (TRAM group), a latissimus dorsi (LD) myocutaneous flap in 27 cases (LD group), and an implant in 26 cases (implant group). The circumference and projection of the neo-nipple were measured using a flexible ruler, immediately after reconstruction and average 10 months after surgery.

Results: The overall circumference and projection at the final measurement were $91.43 \% \pm 7.11 \%$ and $62.16 \% \pm 21.55 \%$, respectively, of immediate postoperative values. The change in circumference did not significantly differ among the 3 groups. In contrast, the change in projection was significantly worse in implant group compared to that in TRAM and LD groups. In addition, among the patients in implant group, greater inflation was significantly associated with greater decrease in the nipple projection.

Conclusion: Breast mound reconstruction with autologous musculocutaneous flap techniques achieves better long-term maintenance of the neo-nipple projection compared to that achieved with expanded tissue and implantation. Considering the prospective loss of long-term nipple dimension, the preoperative design should be oversized in accordance with its origin in mound reconstruction.
\end{abstract}

[Ann Surg Treat Res 2019;96(1):8-13]

Key Words: Mammaplasty, Reconstructive surgical procedures

\section{INTRODUCTION}

Recent trends in breast cancer surgery reflect an increasing proportion of mastectomies with breast reconstruction and a corresponding decreased proportion of breast-conserving therapies [1]. Although nipple-sparing or skin-sparing mastectomies provide superior aesthetic results, their efficacy and effectiveness in the treatment of cancer is still questionable
[2]. In patients with total mastectomy, the creation of a nipple-areola complex $(\mathrm{NAC})$ is the final stage of the breast reconstruction. Although this structure is only noticeable when the patient is undressed, patient satisfaction with the breast reconstruction is highly affected by the completion of this stage. Specifically, patients who undergo NAC reconstruction after breast mound reconstruction show significantly greater satisfaction compared to that in patients who do not undergo
Received April 19, 2018, Revised July 25, 2018, Accepted August 3, 2018

\section{Corresponding Author: Dong Won Lee}

Department of Plastic and Reconstructive Surgery, Institute for Human Tissue Restoration, Yonsei University College of Medicine, 50-1 Yonsei-ro, Seodaemun-gu, Seoul 03722, Korea

Tel: +82-2-2228-2215, Fax: +82-2-393-6947

E-mail:xyphoss@yuhs.ac

ORCID code: https://orcid.org/0000-0003-0046-3139
Copyright (c) 2019, the Korean Surgical Society

(c) Annals of Surgical Treatment and Research is an Open Access Journal. All articles are distributed under the terms of the Creative Commons Attribution NonCommercial License (http://creativecommons.org/licenses/by-nc/4.0/) which permits unrestricted non-commercial use, distribution, and reproduction in any medium, provided the original work is properly cited. 
NAC reconstruction [3].

Although various techniques have been introduced for NAC reconstruction, a flattening of the reconstructed nipple is inevitable. The nipple projection demonstrates a major decrease during the first 3 months after surgery, becoming stable after 6 months, with $29 \%-60 \%$ of the projection reliably maintained over a 1-year follow-up [4-7]. In an effort to allow additional insight into the long-term changes of the reconstructed nipple in accordance with the type of breast mound reconstruction performed, we reviewed a series of patients who underwent nipple reconstruction at our institution.

\section{METHODS}

\section{Patients}

Seventy-eight NAC reconstructions using the C-V flap technique were performed in 78 patients following breast mound reconstruction by a single plastic surgeon. Patients were divided into 3 groups according to the type of breast mound reconstruction: TRAM group underwent free transverse rectus abdominis myocutaneous (TRAM) flap reconstruction, latissimus dorsi (LD) group underwent LD myocutaneous flap reconstruction, and implant group underwent expander and implant-based reconstruction. The study was conducted in accordance with the Helsinki Declaration and was approved by Yonsei University Medical Center Institutional Review Board (approval number: 4-2018-0197). Given the retrospective nature of the study, informed consent was waived.

\section{Surgical procedures}

Nipple reconstruction was performed using a modified C-V flap technique. The tip of V-flap was modified into round shape that resembles U-shape for sufficient perfusion to the tip of flaps [8]. After the dermal flap was elevated, the subcutaneous fat tissue was thinned to prevent tension on the sutures, except at the base of the flap. Thus, the center of the flap had adequate fat tissue to maintain the blood supply and volume. The bilateral wings of the U-shaped flap were folded to form a barrel shape and were sutured with nylon. The skin was deepithelized along the newly constructed nipple base. The C-flap and V-flap donor sites were closed primarily (Fig. 1). Subsequently, nipple caps were applied to minimize external compressive forces on the neo-nipples in all patients.

\section{Assessments}

Nipple projection was measured from the base to the top of the reconstructed nipple, and nipple circumference was measured around the center of the reconstructed nipple using a flexible ruler. The first measure was performed approximately ten days after surgery, and the second measure was performed average 10 months after surgery, at the time when the tattoo procedure was performed. The maintenance was calculated in terms of the percent change from the first measurement to the second measurement. Both measurements were taken in the same manner at the outpatient department. Furthermore, in implant group, we evaluated the total inflationamount of expander before changing to a permanent implant, and analyzed the relationship between the amount of inflation and the change in nipple size.

\section{Statistical analysis}

All statistical analyses were conducted using IBM SPSS Statistics ver. 22.0 (IBM Co., Armonk, NY, USA). Descriptive statistics are presented as means with standard deviations or as numbers and percentages. Group differences were evaluated in 1-way analyses of variance, with Bonferroni correction. In addition, we evaluated the nipple size according to the amount of inflation in implant group using the Pearson correlation coefficient. A P-value $<0.05$ was considered statistically significant.

\section{RESULTS}

A total of 78 nipples were evaluated and the average followup duration was $10 \pm 7$ months. The patient demographics are presented in Table 1; no statistically significant differences were observed among the groups. The overall mean circumference and projection at the final measurement were $91.43 \% \pm$

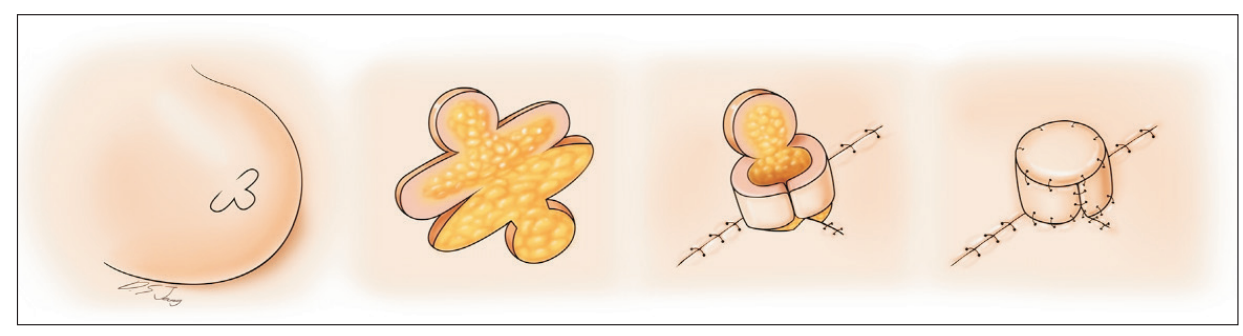

Fig. 1. Nipple reconstruction using a modified C-V flap technique. One C flap and 2 rounded V-flaps were elevated from the reconstructed breast mound while preserving dermis and fat tissue. After thinning of subcutaneous fat tissue, bilateral wings of the rounded V-flap were sutured with nylon. The C-flap and V-flap donor sites were closed primarily. 
$7.11 \%$ and $62.16 \% \pm 21.55 \%$, respectively, of the immediate postoperative values. The decrease in the circumference over time did not significantly differ among the 3 groups (Table 2). In contrast, the decrease in the projection over time was significantly greater in group C $(52.08 \%)$ compared to that in TRAM (66.49\%) and LD (68.39\%) groups ( $<<0.05)$ (Fig. 2), with no significant difference between TRAM and LD groups (Table 2).

In addition, among the patients in implant group, greater inflation was significantly associated with greater decrease in the nipple projection (Fig. 3).

\section{DISCUSSION}

Among various reconstruction methods, including free

Table 1. Patient demographics

\begin{tabular}{lrrr}
\hline \multicolumn{1}{c}{ Variable } & $\begin{array}{c}\text { TRAM } \\
\text { group }\end{array}$ & $\begin{array}{c}\text { LD } \\
\text { group }\end{array}$ & Implant group \\
\hline $\begin{array}{l}\text { Type of breast mound } \\
\text { reconstruction }\end{array}$ & TRAM flap & LD flap & TE + Implant \\
No. of patients & 25 & 27 & 26 \\
Mean age (yr) & 50 & 51 & 48.38 \\
Body mass index $\left(\mathrm{kg} / \mathrm{m}^{2}\right)$ & & & \\
$<25$ (normal weight) & 18 & 20 & 25 \\
25-30 (over weight) & 7 & 6 & 1 \\
>30 (obese) & 0 & 1 & 0 \\
Mastectomy type & & & \\
Total mastectomy & 23 & 26 & 25 \\
Skin-sparing mastectomy & 2 & 1 & 1 \\
TNM stage & & & \\
0 & 9 & 8 & 7 \\
IA & 9 & 14 & 13 \\
IIA & 4 & 3 & 4 \\
IIB & 0 & 1 & 1 \\
IIIA & 0 & 1 & 1 \\
IIIC & 2 & 0 & 0 \\
IV & 1 & 0 & 0 \\
\hline
\end{tabular}

TRAM, transverse rectus abdominis myocutaneous; LD, latissimus dorsi; TE, tissue-expander.

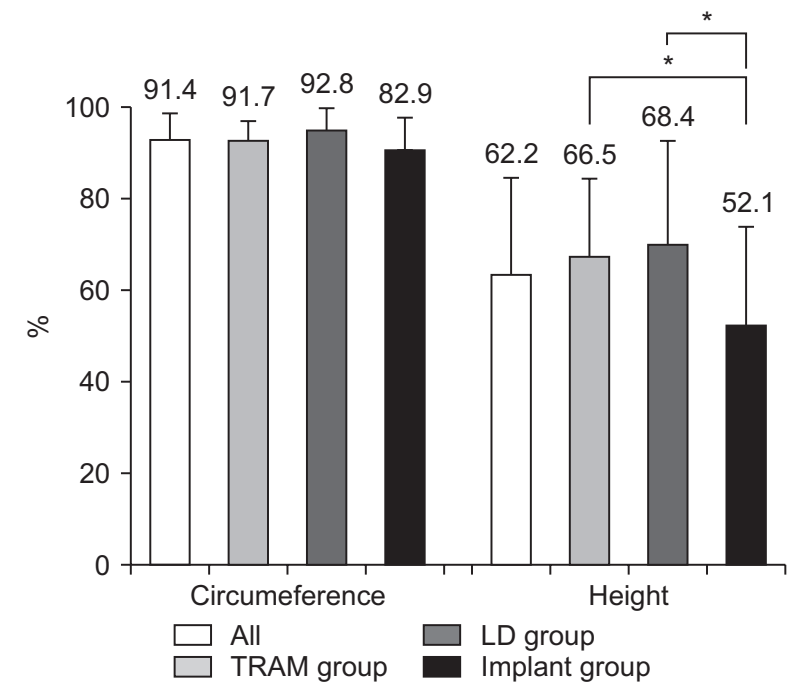

Fig. 2. Comparison of the change in nipple circumference and projection among various reconstruction methods. Nipples from autologous tissue showed more stability than nipples from expanded tissue. ${ }^{*} \mathrm{P}<0.05$.

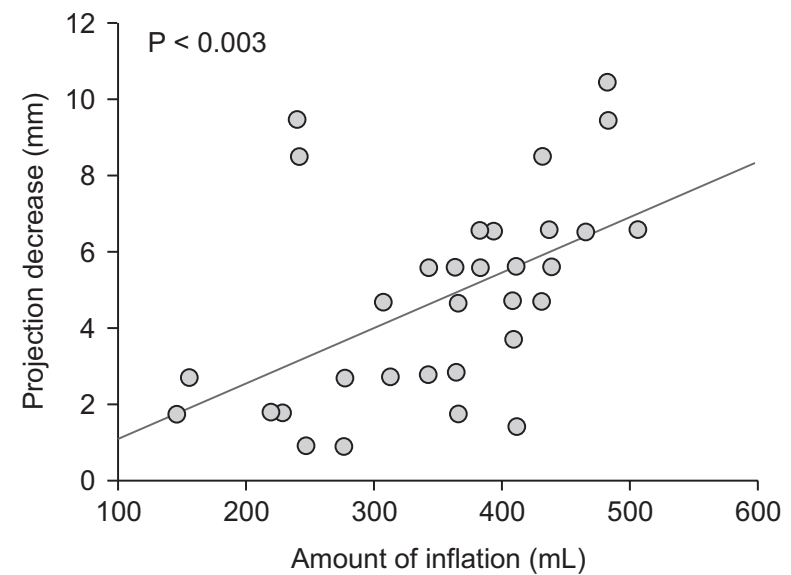

Fig. 3. Pearson correlations and scatterplot depicting the relationship between expansion and nipple projection changes among the patients in implant group. In group $\mathrm{C}$, as the amount of postoperative expansion increases, the rate of projection decrease is greater $(\mathrm{P}<0.003)$.

Table 2. Changes in the reconstructed nipple dimensions

\begin{tabular}{|c|c|c|c|c|c|c|}
\hline \multirow{2}{*}{ Group } & \multicolumn{3}{|c|}{ Circumference (mm) } & \multicolumn{3}{|c|}{ Projection (mm) } \\
\hline & 1st measure & 2nd measure & $\%$ Change & 1 st measure & 2nd measure & $\%$ Change \\
\hline All & $42.53 \pm 6.12$ & $38.83 \pm 6.10$ & $91.43 \pm 7.11$ & $10.09 \pm 2.89$ & $6.08 \pm 2.43$ & $62.16 \pm 21.55$ \\
\hline TRAM & $43.08 \pm 6.01$ & $39.46 \pm 5.57$ & $91.72 \pm 5.79$ & $11.12 \pm 2.14$ & $7.31 \pm 2.05$ & $66.49 \pm 16.68$ \\
\hline LD & $42.92 \pm 6.39$ & $39.71 \pm 6.14$ & $92.75 \pm 7.06$ & $9.08 \pm 2.14$ & $5.91 \pm 2.68$ & $68.39 \pm 23.30$ \\
\hline Implant & $41.62 \pm 6.17$ & $37.38 \pm 6.50$ & $89.92 \pm 8.26$ & $10.00 \pm 2.65$ & $5.00 \pm 2.03$ & $52.08 \pm 21.30$ \\
\hline
\end{tabular}

Values are presented as mean \pm standard deviation.

TRAM, transverse rectus abdominis myocutaneous; LD, latissimus dorsi. 
composite grafts, nipple banking, opposite nipple sharing and tattoo alone, local flaps using the adjacent tissue followed by intradermal tattooing is the currently the most common method. Local flap techniques, such as Anton's star flap, Kroll and Hamilton double opposing tab flap [9], Bostwick C-V flap [10] and their modifications [11-15], have continuously evolved since Little first described the skate flap in 1984 [16]. Although many techniques have been introduced, no specific technique has been proven to be superior. However, in the present study, breast mound reconstruction with autologous musculocutaneous flap techniques was found to achieve better long-term maintenance of the neo-nipple projection compared to that achieved with expanded tissue and implantation.

Several studies have shown a tendency for the reconstructed nipple to shrink over time, especially in terms of the projection, regardless of the reconstruction technique performed. Up to $50 \%$ postoperative shrinkage can occur following conventional nipple reconstruction [17]. A previous study evaluating three different pull-out flap techniques showed that the projection of the reconstructed nipple decreases the most during the first 6 months, $60 \%$ of the projection reliably maintained after 1 year [4]. Similarly, Few et al. [5] reported that a plateau in the shrinkage is reached by approximately 1 year after reconstruction, with an average loss of 59\% in the nipple projection. In addition, Banducci et al. [7] reported that the postoperative shrinkage rate is up to $71 \%$.

The maintenance of the long-term projection of the neonipple is a major challenge for reconstructive surgeons and greatly affects how patients feel about their reconstructed nipple. In a study on patient satisfaction in NAC reconstruction, patients were asked what they disliked most about the reconstructed nipple; more than $50 \%$ of the patients indicated that an excessive flattening of the nipple was most disliked. Previous authors have suggested the use of autologous remote tissue to improve the long-term maintenance of the nipple projection and minimize flattening. Brent and Bostwick first introduced the use of auricular tissue in 1977 [18], and Tanabe et al. [19] reported that 8 nipples reconstructed using auricular cartilage rolled inside bilobed dermal-fat flaps had a $94.6 \%$ maintenance rate. Guerra et al. [20] introduced a technique using an arrow flap with a rib cartilage graft and followed the size of the nipple projection for more than 7 years; the authors reported that all of the neo-nipples achieved an acceptable and reliable maintenance rate. Furthermore, Heitland et al. [17] reported a $25 \%$ decrease in the nipple projection over an average of 1 year after reconstruction using the same method as that in the study by Guerra et al. [20]. Yanaga made a further development, replacing the rolled auricular cartilage with artificial bone, which eliminates the risk of transferring cancerous cells back to the reconstructed breast, reduces donor-site morbidity, and decreases the operative time [21]. In addition, the postoperative nipple projection was maintained in all 100 patients. As a substitute for autologous tissue, acellular dermal matrix was first introduced by Nahabedian in 2005 [22]. AlloDerm (LifeCell Corp., Branchburg, NJ, USA) was used for augmentation in secondary and tertiary nipple reconstruction with an elongated C-flap and C-V flap. This method achieved an acceptable projection, regardless of the type of breast mound reconstruction. In 2007, Garramone and Lam [23] demonstrated the use of AlloDerm in primary nipple reconstruction. The technique involved the use of a modified star dermal flap pattern with the placement of an AlloDerm graft as a central core. However, only $56 \%$ and $47 \%$ maintenance was achieved at one year in the TRAM flap and tissue-expanded groups, respectively. Thus, the use of AlloDerm cannot be the ultimate solution for preventing nipple shrinkage. In contrast, Bernard and Beran [24] demonstrated satisfactory results at an average of 10 months follow-up using an autologous fat graft in cases with insufficient underlying subcutaneous fat.

In a previous study comparing the reconstructed nipple projection between autologous tissue-based mound reconstruction and implant-based reconstruction, the implantbased group showed worse results [13] consistent with the present results. Furthermore, the present study demonstrated a significant relationship between the amount of inflation in implant-based reconstruction and the projection decrease. After implant-based reconstruction, the expanded dermis of the breast mound loses its thickness via elastosis and zonal fragmentation of the elastic fibers [25]. This prevents the elevated dermal flap from being thicker, which results in more wound contraction. In addition, there is internal pressure that is applied to the surface of the breast, which tends to stretch and flatten the surface of the breast over time. Capsules around the implant also provide contractile forces, which leads to further projection loss. The closure of local defects would also create distorting forces onto the reconstructed nipple. Inadequate subcutaneous fat, external pressure, poor flap design, delayed healing, and tissue memory can also induce nipple shrinkage [2].

In autologous-based mound reconstructions, nipples reconstructed from the thicker dermis of the back skin associated with a LD skin island is far more resistant to contraction than are nipples reconstructed from the thinner dermis of a transverse rectus abdominis flap skin island. This is thought to be related to the natural progression of wound contraction during the healing process. Local flaps are elevated from the tissue of the breast mound, including the skin and subcutaneous tissue. Transplanted fatty tissue shrinks over time, whereas the dermal component shows less volume change; thus, flaps from a thick dermal region can better resist flattening. In a previous study on skin thickness in Korean adults, back skin was shown to be the thickest in the body, and chest skin was thicker than abdominal skin [26]. Dermal 
thickness followed the same pattern, while epidermal thickness was greatest in the chest, followed by the abdomen and back.

External pressure, such as wearing a bra, may aggravate the shrinkage. Previous radiation, wound infection, and inappropriate flap design may also compromise the flap circulation, resulting in delayed wound healing and further flattening of the reconstructed nipple. As many circumstances contribute to this unfavorable tendency of reconstructed nipple shrinkage, preoperative plans should be made with great care. Designing the flap as bigger than desired may be the first step in overcoming shrinkage. In our experience, when determining the size of the neo-nipple, all dimensions should be designed larger than those of the opposite side, regardless of the type of breast mound reconstruction. In terms of the nipple projection, if the breast mound is reconstructed with an implant after expansion, a larger design should be considered than that for an autologous-based reconstruction to compensate for future losses. In addition, delicate postoperative care, such as a soft plastic nipple cap, is essential for avoiding secondary dimensional loss.

In conclusion, breast mound reconstruction with autologous musculocutaneous flap techniques achieves better long-term maintenance of the neo-nipple projection compared to that achieved with expanded tissue and implantation. However, as the shrinkage of the neo-nipple is inevitable, the preoperative design should be oversized in accordance with the type of reconstruction of breast mound.

\section{CONFLICTS OF INTEREST}

No potential conflict of interest relevant to this article was reported.

\section{ACKNOWLEDGEMENTS}

The authors thank Mr. Dong-Su Jang, Research Assistant, Department of Anatomy, Yonsei University College of Medicine, Seoul, Korea, for his help with the figures.

\section{REFERENCES}

1. Chang JM, Kosiorek HE, Dueck AC, Casey WJ, Rebecca AM, Mahabir R, et al. Trends in mastectomy and reconstruction for breast cancer; a twelve year experience from a tertiary care center. Am J Surg 2016;212:1201-10.

2. Mota BS, Riera R, Ricci MD, Barrett J, de Castria TB, Atallah ÁN, et al. Nippleand areola-sparing mastectomy for the treatment of breast cancer. Cochrane Database Syst Rev 2016;11:CD008932.

3. Wellisch DK, Schain WS, Noone RB, Little JW 3rd. The psychological contribution of nipple addition in breast reconstruction. Plast Reconstr Surg 1987;80:699-704.

4. Shestak KC, Gabriel A, Landecker A, Peters S, Shestak A, Kim J. Assessment of long-term nipple projection: a comparison of three techniques. Plast Reconstr Surg 2002;110:780-6.

5. Few JW, Marcus JR, Casas LA, Aitken ME, Redding J. Long-term predictable nipple projection following reconstruction. Plast Reconstr Surg 1999;104:1321-4.

6. Kroll SS, Reece GP, Miller MJ, Evans GR, Robb GL, Baldwin BJ, et al. Comparison of nipple projection with the modified double-opposing tab and star flaps. Plast Reconstr Surg 1997;99:1602-5.

7. Banducci DR, Le TK, Hughes KC. Longterm follow-up of a modified AntonHartrampf nipple reconstruction. Ann Plast Surg 1999:43:467-9.

8. Yun IS, Lew DH, Tark KC. Nipple Reconstruction with Modified C-V Flap: C-U Flap. J Korean Soc Aesthetic Plast Surg 2008;14:75-8.

9. Kroll SS, Hamilton S. Nipple reconstruction with the double-opposing-tab flap. Plast Reconstr Surg 1989;84:520-5.

10. Losken A, Mackay GJ, Bostwick J 3rd. Nipple reconstruction using the C-V flap technique: a long-term evaluation. Plast Reconstr Surg 2001;108:361-9.

11. El-Ali K, Dalal M, Kat CC. Modified C-V flap for nipple reconstruction: our results in 50 patients. J Plast Reconstr Aesthet Surg 2009;62:991-6.

12. Mori H, Hata Y. Modified C-V flap in nipple reconstruction. J Plast Reconstr Aesthet Surg 2008;61:1109-10.

13. Eo S, Kim SS, Da Lio AL. Nipple recons- truction with C-V flap using dermofat graft. Ann Plast Surg 2007;58:137-40.

14. Zhong T, Antony A, Cordeiro P. Surgical outcomes and nipple projection using the modified skate flap for nippleareolar reconstruction in a series of 422 implant reconstructions. Ann Plast Surg 2009;62:591-5.

15. Eskenazi L. A one-stage nipple reconstruction with the "modified star" flap and immediate tattoo: a review of 100 cases. Plast Reconstr Surg 1993;92:671-80.

16. Little JW 3rd. Nipple-areola reconstruction. Clin Plast Surg 1984:11:351-64.

17. Heitland A, Markowicz M, Koellensperger E, Allen R, Pallua N. Long-term nipple shrinkage following augmentation by an autologous rib cartilage transplant in free DIEP-flaps. J Plast Reconstr Aesthet Surg 2006;59:1063-7.

18. Brent B, Bostwick J. Nipple-areola reconstruction with auricular tissues. Plast Reconstr Surg 1977;60:353-61.

19. Tanabe HY, Tai Y, Kiyokawa K, Yamauchi T. Nipple-areola reconstruction with a dermal-fat flap and rolled auricular 
cartilage. Plast Reconstr Surg 1997; 100:431-8.

20. Guerra AB, Khoobehi K, Metzinger SE, Allen RJ. New technique for nipple areola reconstruction: arrow flap and rib cartilage graft for long-lasting nipple projection. Ann Plast Surg 2003;50:31-7.

21. Yanaga H. Nipple-areola reconstruction with a dermal-fat flap: technical improvement from rolled auricular cartilage to artificial bone. Plast Reconstr Surg 2003;112:1863-9.

22. Nahabedian MY. Secondary nipple reconstruction using local flaps and AlloDerm. Plast Reconstr Surg 2005;115: 2056-61.

23. Garramone CE, Lam B. Use of AlloDerm in primary nipple reconstruction to improve long-term nipple projection. Plast Reconstr Surg 2007;119:1663-8.
24. Bernard RW, Beran SJ. Autologous fat graft in nipple reconstruction. Plast Reconstr Surg 2003;112:964-8.

25. Matturri L, Azzolini A, Riberti C, Lavezzi AM, Cavalca D, Vercesi F, et al. Long-term histopathologic evaluation of human expanded skin. Plast Reconstr Surg 1992;90:636-42.

26. Lee Y, Hwang K. Skin thickness of Korean adults. Surg Radiol Anat 2002;24:183-9. 